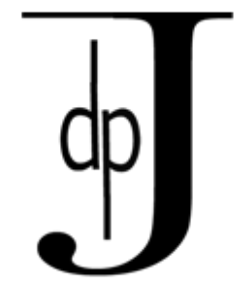

\title{
Dialogic Pedâgogy
}

\section{Dialogue-based teaching: The art museum as a learning space}

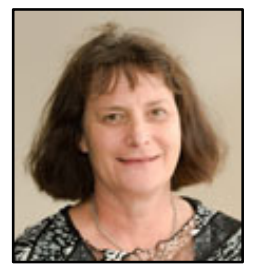

Jeanette Clarkin-Phillips

The University of Waikato, New Zealand

\begin{abstract}
Book review: Olga Dysthe, Nana Bernhardt \& Line Esbjørn (2013). Dialogue-based teaching. The art museum as a learning space. Copenhagen, Denmark: Skoletjenesten.
\end{abstract}

Dialogue-based teaching: the art museum as learning space by authors Dysthe, Bernhardt and Esbjørn opens up opportunities for museum educators, in particular, to engage with ideas based on dialogue -based teaching. Using concepts from a range of dialogic theorists, case studies of teaching sequences in seven different museums are presented and analysed. The purpose of the book is to promote good teaching practice and encourage the use of museums and art galleries as alternative learning spaces for promoting citizenship.

Not being particularly familiar with dialogic theories and philosophies, I found the outlining of the significant contributors to this field near the outset was helpful, as was the description of the common or central concepts identified by the research that exemplified dialogic conversations. Using Martin Nystrand's dialogic concept of authentic questions and uptake as well as Dysthe's multivoicedness the authors show how these concepts can provide rich learning opportunities in the museum space.

The most telling comment in the book, for me was "dialogue-based teaching functions as well as it does even though it is subject to the limitations of a museum visit" (p.189). Even though this comment was in relation to a specific case study it illustrates the careful and thorough description and analysis of the seven case studies. There is no attempt to sanitise what happens in the interactions between museum educators and students but highlights the dialogue-based strategies employed by the educator to maximise the opportunities despite the constraints of the context. The case studies demonstrate the potential of dialogue to engage students in learning, solicit responses and conscript participation in a situation that is time bound and contextually foreign to many of the students. Although as classroom teachers or teachers in early childhood centres we may have multitude opportunities throughout the day to dialogue with children and in many respects may be in an almost ideal situation to employ dialogic practices, the museum visit requires skilled educators to develop a dialogic relationship with students.

Research carried out by myself and a colleague with preschool children and their teachers developing a relationship with a museum, has found that it is the dialogue and reciprocal listening and 
conversing between teacher and children that provides the opportunities for meaning-making, expressing ideas and taking others' points of view (Carr, Clarkin-Phillips, Beer, Thomas \& Waitai, 2012). These conversations make interesting and unpredictable deviations depending on the working theories of the young children but it is the skill of the teacher that allows for dialogue to continue rather than hijacking the children's interest. This tension is highlighted in the book in the discussion about time constraints, student's familiarity with the context and preparedness for the visit as well as the purpose of the visit.

The last chapter of the book was significant in allaying my unease about how the case studies might be useful for further dialogue amongst a range of educators. In its provision of recommendations for dialogue-based teaching there is the potential for the future dialogue about the nature, structure and characteristics of such an approach to teaching. It may be that some supporters of dialogic pedagogy would disregard the inclusion of multi-modal forms of expression in favour of a purist view of 'conversation' as dialogue. This is worth further debate.

This book has much to offer museum educators and teachers who are committed to dialoguebased pedagogies offering a range of examples for practice and discussion. The book is a useful reminder of the power of dialogue to engage, stimulate curiosity and creativity while providing authentic opportunities for the multivoicedness of a group to be heard. For those educators who may be unfamiliar with the concepts and theories of dialogue-based teaching and their relationship to citizenship, this book is a worthwhile resource for developing an understanding of both theory and practice.

In outlining the power of dialogue-based teaching within the museum as a learning space for students, I wondered how this approach might be employed generally in the museum to enhance the public's interactions with the museum. I am left with the question: how might dialogue be encouraged in a public space to enhance democratic citizenship and create opportunities for listening to other's perspectives?

\section{(cc) EY}

Articles in this journal are licensed under a Creative Commons Attribution 3.0 United States License.

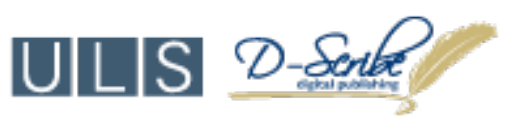

This journal is published by the University Library System, University of Pittsburgh as part of its D-Scribe Digital Publishing Program and is cosponsored by the University of Pittsburgh Press. 